Original Contribution

\title{
HEME OXYGENASE-1 EXPRESSION AND OXIDATIVE STRESS - RELATED MARKERS IN GASTRIC MUCOSA IN SKIN BURNS AND PROTECTION WITH MELATONIN
}

\author{
M. Hristova ${ }^{1}$, G. Bekyarova ${ }^{1}$, M. Tzaneva ${ }^{2}$ \\ ${ }^{1}$ Divison of Pathophysiology, Faculty of Medicine, Medical University of Varna, Bulgaria \\ ${ }^{2}$ Department of Clinical and Preclinical Sciences, Faculty of Pharmacy, \\ Medical University of Varna, Bulgaria
}

\begin{abstract}
Melatonin, a major hormone of pineal gland, was recently show to attenuate acute gastric lesions induced by strong irritants because of the scavenging of free radicals. The effect of melatonin on burninduced gastric mucosal injury due to the skin burn is unclear. PURPOSE: This study investigated heme oxygenase-1 and markers linked with oxidative stress in gastric mucosa and the effect of melatonin in burn rat model. METHODS: Melatonin was applied immediately and 12 hours after 30\% of total body surface area burns. Using light immunohistochemistry the expression of gastric mucosal inducible nitric oxide synthase (iNOS) and heme oxygenase (HO-1) was found out. Malondialdehyde (MDA) as a marker of oxidative injury was determined in gastric mucosa by the thiobarbituric acid method. RESULTS: Gastric MDA and iNOS levels were increased significantly after severe burn $(\mathrm{p}<0.05$, $\mathrm{p}<0.0001$, respectively). The increased HO-1 expression in the burned group was found out $(\mathrm{p}<0.05)$. Melatonin restricted the increased MDA $(\mathrm{p}<0.05)$ and iNOS $(\mathrm{p}<0.05)$ levels, and augmented the increase in HO-1 expression in gastric mucosa $(\mathrm{p}<0.05)$. In conclusion, melatonin ameliorates gastric mucosal injury via induction of antioxidant enzyme HO-1 and inhibition of oxidative stress beyond local burn skin injury.
\end{abstract}

Key words: melatonin, gastric mucosa, HO-1, oxidative stress, burn injury

\section{INTRODUCTION}

Thermal skin injury leads to local tissue destruction and adaptive response with is associated with splanchnic vasoconstriction, polymorphonuclear (neutrophils, macrophages) cells infiltration. Ischemia and consequently reperfusion and PMN activation initiated series events including proinflammatory cytokines secretion and generation of reactive oxygene species (ROS) and reactive nitrogen species (RNS) too (1).

Although the exact mechanism involved in burn-induced mucosal damage is not clear yet, increasing evidences indicates decreased gastric mucosal blood flow, local and systemic liberation of cytokines and reactive oxidant intermediaries and changes in production of nitric oxide (NO) and prostaglandins (PGs) as a factor of mucosal damage (2-4).

\footnotetext{
*Correspondence to: Minka Hristova, Divison of Pathophysiology, Faculty of Medicine, Medical University-Varna; 55 Marin Drinov Str., Varna 9002, Bulgaria; E-mail: hristova_minka@abv.bg
}

Heme oxygenase 1 (HO-1) as one of the two isoforms of heme oxygenase is expressed constitutively in normal gastrointestinal tract (GIT). Induction of HO-1 is recently identified as an important cellular mechanism against oxidative stress $(5,6)$. HO-1 expression is elicited in response to hypoxia, ischemia and exposure to proinflammatory cytokines, nitric oxide (NO) and heme (7). Recent studies indicate that HO-1, also known as heat shock proteins HSP32, may play an important role in gastrointestinal tissues protection by ischemia reperfusion, ethanol and non-steroidal antiinflammatory drugs (NSAID) (8-11). Drugs such as sofalkone and zinc-I-carnosin may protect against gastrointestinal injury by $\mathrm{HO}-1$ induction $(12,13)$. The role of HO-1 in burninduced gastric mucosal injury remains unclear.

Melatonin (N-acetyl-5-methoxy tryptamine), a basic secretory product of the pineal gland, has a wide variety of biological activity including antioxidant and anti-inflammatory effects (14, 15). Melatonin is powerful antioxidant and 
HRISTOVA M., et al.

scavenger, especially of reactive oxygen and nitrogen species restricting their proinflammatory and membrane-damaging effect (16). It stimulates expression of antioxidant enzymes including $\mathrm{Cu} / \mathrm{Zn}$ superoxide dismutase $(\mathrm{Cu} / \mathrm{ZnSOD})$ and glutathione peroxidase (GSH-Px) (17, 18). Melatonin inhibites secretion of pro-inflammatory cytokines and acute phase protein secretion and enzymes with pro-inflammatory and prooxidant action, such as inducible nitric oxide synthase (iNOS) (19-21).

Melatonin was originally implicated in the mechanism of gastric mucosal integrity and in gastric protection against various irritants such as ethanol, stress, NSAID (e.g. aspirin) and ischemia/reperfusion (22). Melatonin enhances gastric mucosal flow and attenuates neutrophil infiltration, oxygen intermediate cytotoxicity and prooxidative damage of gastric mucosa. These effects of melatonin are mediated in part by NO/NOS and PG/COX systems.

The aim of the present study was to explore the protective effect of melatonin on gastric mucosal injury by assessing the expression of HO-1 and other oxidative stress related markers (MDA and iNOS) in burn rat model.

\section{MATERIALS AND METHODS Animals}

All procedures were conducted in compliance with the national laws and policies, in conformity with the international guidelines. Age-matched male rats weighing between 220 and $250 \mathrm{~g}$ fasted for $12 \mathrm{~h}$ were allowed free access to water before injury. Animals were housed in a $20^{\circ} \mathrm{C}$ and offered rat food and water ad libitum. They were kept in dark/light cycles $(\mathrm{DL}=12 / 12 \mathrm{~h})$ in individual wirebottomed cages. Thus, lights were turned off at 8:00 p.m. and turned on at 8:00 a.m. for achieving satisfactory photoperiod.

\section{Thermal injury and melatonin treatment}

After light ether inhalation, general anesthesia was performed using thiopental $(30 \mathrm{mg} / \mathrm{kg}$ i.p.). In order to accomplish $30 \%$ of third degree burn hot boiling water $\left(98^{\circ} \mathrm{C}\right)$ was applied on the back of the animals during a period of $10 \mathrm{sec}$. For those rats which were subjected to burn injury $4 \mathrm{~mL}$ of physiological saline was applied i.p. for immediate resuscitation following burn injury. No animals died within the first $24 \mathrm{~h}$ of post-burn period. Forty-four male rats were randomly assigned to three groups: non-burned rats (controls $(\mathrm{C}, \mathrm{n}$ = 6)); burned, non-treated $(\mathrm{B}, \mathrm{n}=19)$; and melatonin-treated, burned rats $(\mathrm{B}+\mathrm{M}, \mathrm{n}=19)$. Either melatonin (N-acetyl-5-methoxy tryptamine, Merck, Germany) in a dose of 10 $\mathrm{mg} / \mathrm{kg}$ body weight (b.w.), dissolved in vehicle, or vehicle (2\% ethyl alcohol diluted in physiological saline in a dose $5 \mathrm{ml} / \mathrm{kg}$ ) was administered, respectively. Melatonin and vehicle were applied i.p. twice - immediately after burns in the morning between 8:00 a.m. and 9:00 a.m. and 12hours after burn injury. All the animals were given buprenorphine $(0.3$ $\mathrm{mg} / \mathrm{kg}$ i.p. b.w.) twice daily for pain control post burn. The animals from the all groups were anesthetized with thiopental and euthanized $24 \mathrm{~h}$ after burns, and stomach was sampled.

\section{Biochemical analysis}

Stomach was gently separated from the underlying tissue and homogenized in 1:5 w/v $50 \mathrm{mM}$ phosphate buffer ( $\mathrm{pH}$ 7.4) containing $0.1 \mathrm{mM}$ EDTA at $4000 \mathrm{rpm}$ for $10 \mathrm{~min}$. The homogenate was centrifuged at $800 \mathrm{x} \mathrm{g} \mathrm{rpm}$ for 15 min to discard the sediment and supernatant was frozen until analysis. All the manipulations were performed at $4-8^{\circ} \mathrm{C}$. Analysis was carried out immediately after thawing of the samples.

Membrane lipid peroxidation was assayed by MDA measured by its thiobarbituric acid (TBA) reactivity of stomach homogenate using the method of Porter et al. (23). Results were expressed as nmol MDA/g tissue. They were determined using the extinction coefficient of MDA-TBA complex at $532 \mathrm{~nm}=1.56 \times 10^{-5}$ $\mathrm{cm}^{-1} \mathrm{M}^{-1}$ solution.

\section{Immunohistochemistry}

Rat stomach specimens were fixed in 10\% neutral buffered formalin and embedded in paraffin. The deparaffinized and dehydrated sections $(5 \mu \mathrm{m}$ thick) were treated with $1 \%$ hydrogen peroxide for peroxidase activity inhibition for $5 \mathrm{~min}$. Then they were rinsed in $0.1 \mathrm{M}$ phosphate buffered saline (PBS) $(\mathrm{pH}$ 7.4) and treated in normal goat serum for 20 min. Subsequently, the sections were incubated with polyclonal primary antibody for $24 \mathrm{~h}$ at room temperature. Rabbit anti-iNOS (DAKO, USA) and anti -HO-1 antibody (Santa Cruz, USA) was used. After rinsing with PBS the sections were incubated for $20 \mathrm{~min}$ in goat anti-rabbit immunoglobulins at room temperature. Then they were rinsed in PBS again, treated with rabbit peroxidase-antiperoxidase complex for $20 \mathrm{~min}$ at room temperature and then rinsed in PBS. Finally, peroxidase activity was estimated by the diaminobenzydinetetrachloride $\mathrm{H}_{2} \mathrm{O}_{2}$-method. Negative controls were incubated with nonimmune sera instead of primary antibody. Morphometric method was used to assess quantitatively enzyme contents of iNOS and 
HRISTOVA M., et al.

HO-1. Enzyme content was determined as: strong, score 3; moderate, score 2; weak, score 1 , and lacking, score 0 on the basis of the occurrence of immunodeposits (24). iNOS and HO-1 contents of the gastric mucosal cells were defined as the enzyme content of each cell was multiplied by their scoring factors and divided by total number of cells. Morphometric investigation was performed on 100 cells from each sample.

\section{Statistical analysis}

GraphPad Prism software 6.0 was used for statistical analysis. The statistical analysis of differences in the iNOS and HO-1 expression levels was performed using the Mann-Whitney test. The statistical significance of difference was evaluated with the Student's t-test for biochemical analysis. Differences were considered to be statistically significant at a $p$ value of $<0.05$.

\section{RESULTS}

\section{MDA levels in gastric mucosa}

In burn group gastric mucosal MDA level was significantly increased by $42 \% \quad(\mathrm{p}<0.05)$ compared to control group. Melatonin treatment significantly decreased the elevation of MDA in gastric mucosa by $20 \%(\mathrm{p}<0.05)$ than this of the burned group (Figure 1).

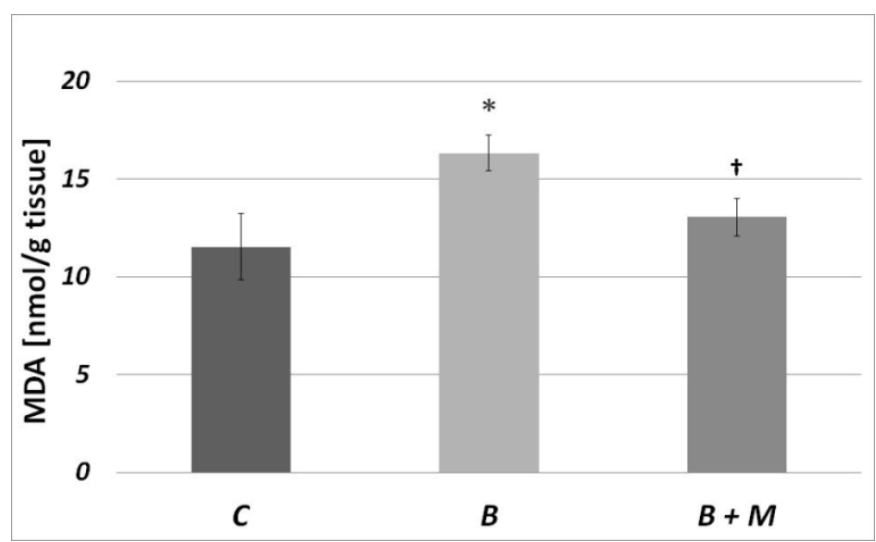

Figure 1. Effect of melatonin on MDA levels in gastric mucosa after burns. Results are given as means $\pm \mathrm{SEM}$. ${ }^{*} \mathrm{p}<0.05$ vs. control group; ${ }^{\dagger} \mathrm{p}<0.05$ vs. burned, non - treated group. Controls (C); burned rats (B); burned rats, treated with melatonin $(\mathrm{B}+\mathrm{M})$.

\section{iNOS expression in gastric mucosa}

The iNOS positive cells in control group were localized mainly in the basal part of gastric mucosa (Figure 2A). The iNOS expression was low and it was localized in cell cytoplasm. The mean content was $0.64 \pm 0.077$. In the burned group, iNOS expression was found mainly in the epithelial cells in the upper part of the stomach glands (Figure 2B). iNOS immunostaining was cytoplasmic and predominate moderate expression. The mean cell content was $1.53 \pm 0.076$. It was significantly higher $(139 \%, \mathrm{p}<0.0001)$ than this of the control group. In the melatonintreated group, iNOS positive cells were localized mainly in the upper half of the gastric mucosa (Figure 2C). The expression was cytoplasmic and the mean cell content was $1.28 \pm 0.059$. It was significantly higher $(100 \%, p<0.0001)$ than this of the control group, but was significantly lower $(16 \%$, $\mathrm{p}<0.05)$ than that in the burned group. The differences of iNOS expression in the groups are presented in Figure 3.

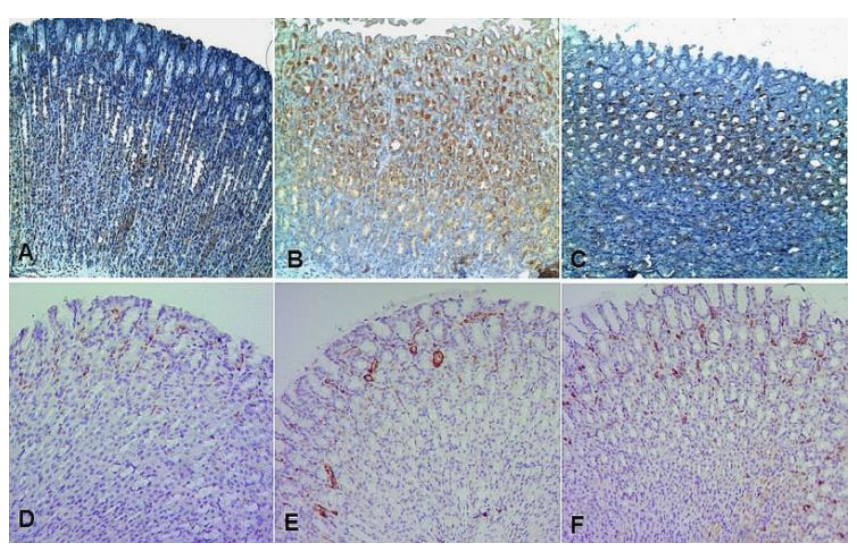

Figure 2 . Effect of melatonin on the expression of inducible nitric oxide synthase (iNOS) in gastric mucosa after burns. Immunohistochemistry detection for iNOS in gastric mucosa. Controls (A); burned rats (B); burned rats, treated with melatonin $(\mathrm{C})$. Effect of melatonin on the expression of heme-oxygenase-1 (HO-1) in gastric mucosa after burns. Immunohistochemistry detection for HO-1 in gastric mucosa. Controls (D); burned rats (E); burned rats, treated with melatonin (F); (Original magnification, x 200). 


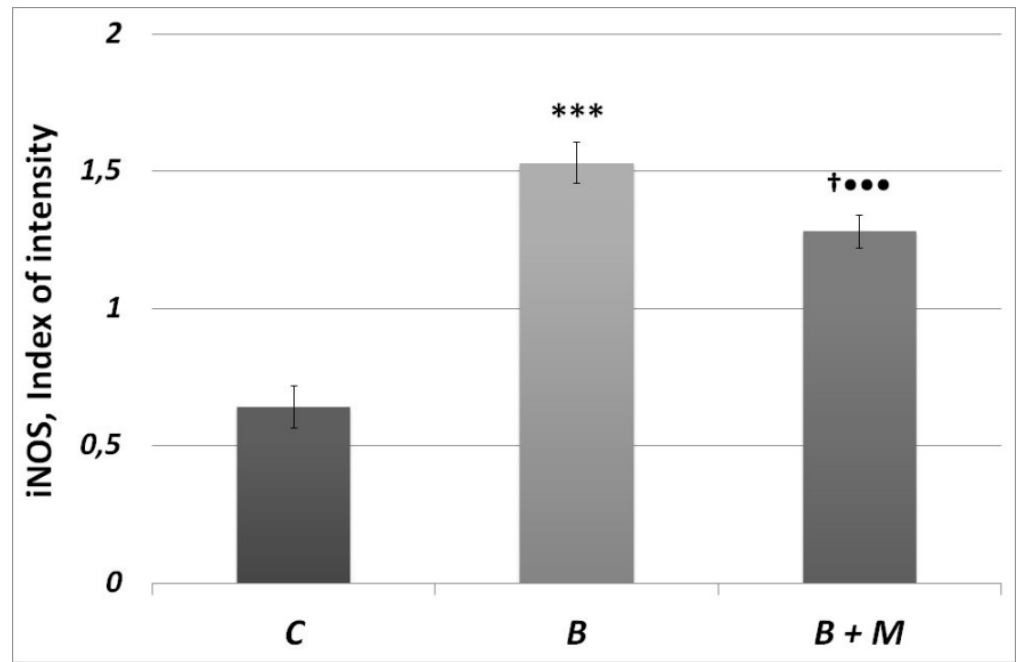

Figure 3. Score index of iNOS positive immunostained cells. Results are given as means \pm SEM. ${ }^{* * * *} \mathrm{p}<0.0001$ vs. control group; ${ }^{\dagger} \mathrm{p}<0.05$ vs. burned, non - treated group; ${ }^{\cdots} \mathrm{p}<0.0001$ vs. control group. Controls (C); burned rats $(\mathrm{B})$; burned rats, treated with melatonin $(\mathrm{B}+\mathrm{M})$.

\section{HO-1 expression in gastric mucosa}

HO-1 expression was low in the control group. Positive for HO-1 were the endothelial cells, which were localized in the upper part of the mucosa (Figure 2D). The mean HO-1 cell content was $1.47 \pm 0.077$. In the burned group, HO-1 content of the endothelial cells was moderate. The localization of HO-1 expression was similar to control group (Figure 2E). The mean cell content was $1.73 \pm$ 0.082 . It was significantly higher $(18 \%$, $\mathrm{p}<0.05)$ than this of the control rats. HO-1 expression in the melatonin-treated group was moderate to high. It was found in both endothelial cells and epithelial cells (Figure 2F). The mean cell content was $2.02 \pm 0.09$. It was significantly higher $(17 \%, \mathrm{p}<0.05)$ than this of the burned rats and was significantly higher $(37 \%, p<0.0001)$ than that of the control rats too. The differences of HO-1 expression in the groups are presented in Figure 4.

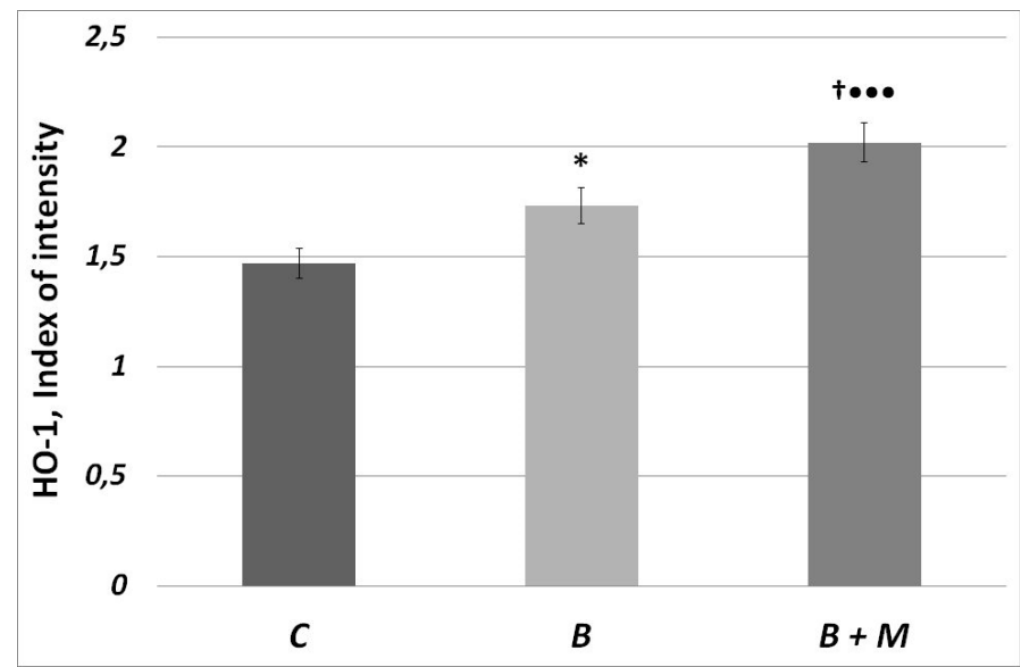

Figure 4. Score index of of HO-1 positive immunostained cells. Results are given as means \pm SEM. ${ }^{*} \mathrm{p}<0.05 \mathrm{vs}$. control group; ${ }^{\dagger} \mathrm{p}<0.05$ vs. burned, non - treated group; ${ }^{\cdots} \mathrm{p}<0.0001 \mathrm{vs}$. control group. Controls (C); burned rats (B); burned rats, treated with melatonin $(\mathrm{B}+\mathrm{M})$.

\section{DISCUSSION}

The present study demonstrates that burn trauma increases levels of oxidative stressrelated marker MDA and HO-1 expression in gastric mucosa. Melatonin treatment decreases burn-induced oxidative mucosal damage and augmented increase of HO-1 expression.

Burn skin injury causes ischemia/reperfusion injury and neutrophil infiltration in splanchnic system which leads to increase production of
ROS and proinflammatory mediators $(25,1)$. ROS and proinflammatory cytokines activate iNOS, an inducible form of NOS enzymes catalyzing the production of nitric oxide (NO) from L-arginine (26). In the present study, iNOS is significant increased in gastric mucosa after the thermal injury. Excessive production of NO/iNOS leads to tissue damage and organ dysfunction, because NO reacts with superoxide leading to peroxynitrite formation (27). Overproduction of ROS/RNS activates 
HRISTOVA M., et al.

lipid peroxidation, evidenced by increased MDA levels in gastric mucosa at 24 hours after burn trauma. It has been reported that the increased lipid peroxidation levels in plasma $(19,28)$ and gastric mucosa (29), and the decreased antioxidant defense cause oxidative damage of gastric mucosa, induced by burns (29), NSAID, ethanol, cold/restraint stress treatment (30).

Melatonin is free radical scavenger that directly interacts with a variety of oxygen and nitrogen-based radicals - hydrogen peroxide, singlet oxygen, peroxynitrite anion, nitric oxide and hypochlorous acid. Its metabolites participate in the detoxification too $(31,32)$. Melatonin administration decreases lipid peroxidation and increases antioxidant enzyme activities in gastric tissues of rats (33) and enhancing HO-1 induction, and reduces tissue injury (34).

Increased production of ROS/RNS induces adaptive response and increases activity of antioxidant defense system and supported cells homeostasis $(35,36)$. While oxidative stress can lead to suppression of antioxidants enzyme activity (SOD, CAT) and decreased levels of GSH (37-39). In this manner imbalanced antioxidant system and increased production of ROS/RNS cause gastric mucosal damage, evidenced by histological changes after burn (40).

ROS/RNS and inflammatory mediators are part of the main HO-1 activators (5, 7). HO-1 catalyses heme degradation producing $\mathrm{CO}$, which has anti-inflammatory properties; biliverdin converted to bilirubin, a powerful antioxidant, by biliverdin reductase (BVR); and free iron bound to the heavy chain ferritin (H-ferritin), another antioxidant molecule. The inducible, redox-sensitive, isoform of $\mathrm{HO}$ (HO-1) is involved in protection against inflammation and oxidative stress in different pathological conditions (41). Our investigations shows that HO-1 expression in gastric mucosa increases after burn trauma (42).

HO- 1 and its products can decrease the activity of transcription factor NF- $\mathrm{BB}$, activity of proinflammatory enzyme iNOS and overproduction of NO (43). We suggest that a decrease of $\mathrm{NO}$ and superoxide production by melatonin inhibits formation of toxic peroxynitrite and has gastroprotective effect under condition of oxidative stress after burn. Our results show that melatonin reduces oxidative gastric mucosal injury by upregulation of antioxidant enzyme $\mathrm{HO}-1$. We can hypothesize that HO-1 induction and followed reducing NO/iNOS production is a new mechanism of melatonin's gastroprotection in burns.

\section{CONCLUSIONS}

Skin burn induces oxidative gastric mucosal injury by increased MDA levels and iNOS expression, and adaptive HO-1 expression. Melatonin significantly restricts burn-induced gastric mucosal injury by augmentation of $\mathrm{HO}-$ 1 expression and decreases the level of other oxidative stress-related markers.

\section{REFERENCES}

1. Schwacha, M.G., Macrophages and postburn immune dysfunction. Burns, 29(1):114. Review, 2003.

2. Yoshida, M., Kurose, I., Wakabayashi, G., Hokari, R., Ishikawa, H., Otani, Y., Shimazu, M., Miura, S., Ishii, H. and Kitajima, M., Suppressed production of nitric oxide as a cause of irregular constriction of gastric venules induced by thermal injury in rats. J Clin Gastroenterol, 25 Suppl 1:S56-60, 1997.

3. Rawlingson, A., Nitric oxide, inflammation and acute burn injury. Burns, 29(7):631-40, 2003.

4. Battal, M.N., Hata, Y., Matsuka, K., Ito, O., Matsuda, H., Yoshida, Y., Kawazoe, T. and Nagao, M., Effect of a prostaglandin I2 analogue, beraprost sodium, on burninduced gastric mucosal injury in rats. Burns, 23(3):232-7, 1997.

5. Bach, F.H., Heme oxygenase-1 as a protective gene. Wien Klin Wochenschr, 114 Suppl 4:1-3. Review, 2002.

6. Ryter, S.W., Alam, J. and Choi, A.M., Heme oxygenase-1/carbon monoxide: from basic science to therapeutic applications. Physiol Rev, 86(2):583-650, 2006.

7. Otterbein, L.E. and Choi, A.M., Heme oxygenase: colors of defense against cellular stress. Am J Physiol Lung Cell Mol Physiol, 279(6):L1029-37, 2000.

8. Vicente, A.M., Guillén, M.I., Habib, A. and Alcaraz, M.J., Beneficial effects of heme oxygenase-1 up-regulation in the development of experimental inflammation induced by zymosan. $J$ Pharmacol Exp Ther, 307(3):1030-7, 2003.

9. Aburaya, M., Tanaka, K., Hoshino, T., Tsutsumi, S., Suzuki, K., Makise, M., Akagi, R. and Mizushima, T., Heme oxygenase-1 protects gastric mucosal cells against non-steroidal anti-inflammatory drugs. J Biol Chem, 281(44):33422-32, 2006.

10.Gomes, A.S., Gadelha, G.G., Lima, S.J., Garcia, J.A., Medeiros, J.V., Havt, A., 
Lima, A.A., Ribeiro, R.A., Brito, G.A., Cunha F.Q. and Souza, M.H., Gastroprotective effect of heme-oxygenase 1/biliverdin/CO pathway in ethanol-induced gastric damage in mice. Eur J Pharmacol, 642(1-3):140-5, 2010.

11.Uc, A., Zhu, X., Wagner, B.A., Buettner, G.R. and Berg, D.J., Heme oxygenase-1 is protective against non-steroidal antiinflammatory drug-induced gastric ulcers. $J$ Pediatr Gastroenterol Nutr, 54(4):471-6, 2012.

12.Ueda, K., Ueyama, T., Oka, M., Ito, T., Tsuruo, Y. and Ichinose, M., Polaprezinc (Zinc L-carnosine) is a potent inducer of anti-oxidative stress enzyme, heme oxygenase (HO)-1 - a new mechanism of gastric mucosal protection. J Pharmacol Sci, 110(3):285-94, 2009.

13.Shibuya, A., Onda, K., Kawahara, H., Uchiyama, Y., Nakayama, H., Omi, T., Nagaoka, M., Matsui, H. and Hirano, T., Sofalcone, a gastric mucosa protective agent, increases vascular endothelial growth factor via the Nrf2-heme-oxygenase-1 dependent pathway in gastric epithelial cells. Biochem Biophys Res Commun, 398(3):581-4, 2010.

14.Reiter, R.J., Tan, D.X. and Burkhardt, S., Reactive oxygen and nitrogen species and cellular and organismal decline: amelioration with melatonin. Mech Ageing Dev, 123(8):1007-19, 2002.

15.Tan, D.X., Manchester, L.C., Terron, M.P., Flores, L.J. and Reiter, R.J., One molecule, many derivatives: a never-ending interaction of melatonin with reactive oxygen and nitrogen species? J Pineal Res, 42(1):28-42, 2007.

16.Korkmaz, A., Reiter, R.J., Topal, T., Manchester, L.C., Oter, S. and Tan, D.X., Melatonin: an established antioxidant worthy of use in clinical trials. Mol Med, 15(1-2):43-50, 2009.

17.Reiter, R., Tang, L., Garcia, J.J. and Muñoz-Hoyos, A., Pharmacological actions of melatonin in oxygen radical pathophys iology. Life Sci, 60(25):2255-71, 1997.

18.Rodella, L.F., Favero, G., Rossini, C., Foglio, E., Reiter, R.J. and Rezzani, R., Endothelin-1 as a potential marker of melatonin's therapeutic effects in smokinginduced vasculopathy. Life Sci, 87(1718):558-64, 2010.

19.Bekyarova, G., Tancheva, S. and Hristova, M., The effects of melatonin on burninduced inflammatory responses and coagulation disorders in rats. Methods Find Exp Clin Pharmacol, 32(5):299-303, 2010.
20.Dong, W.G., Mei, Q., Yu, J.P., Xu, J.M., Xiang, L. and $\mathrm{Xu}, \mathrm{Y}$., Effects of melatonin on the expression of iNOS and COX-2 in rat models of colitis. World $J$ Gastroenterol, 9(6):1307-11, 2003.

21.Mauriz, J.L., Collado, P.S., Veneroso, C., Reiter, R.J. and González-Gallego, J., A review of the molecular aspects of melatonin's anti-inflammatory actions: recent insights and new perspectives. $J$ Pineal Res, 54(1):1-14, 2013.

22.Brzozowska, I., Ptak-Belowska, A., Pawlik, M., Pajdo, R., Drozdowicz, D., Konturek, S.J., Pawlik, W.W. and Brzozowski, T., Mucosal strengthening activity of central and peripheral melatonin in the mechanism of gastric defense. J Physiol Pharmacol, 60 Suppl 7:47-56, 2009.

23.Porter, N.A., Nixon, J.R. and Isaac, R., Cyclic peroxidase and thiobarbituric assay. Biochem Biophys Acta, 441, 596-599, 1976.

24.Tzaneva, M.A., Electron microscopic immunohistochemical investigation of chromogranin $\mathrm{A}$ in endocrine cells in human oxyntic gastric mucosa. Acta Histochem, 103(2):179-94, 2001.

25.Sasaki, M. and Joh, T., Oxidative stress and ischemia-reperfusion injury in gastrointestinal tract and antioxidant, protective agents. J Clin Biochem Nutr, 40(1):1-12, 2007.

26.Andrew, P.J. and Mayer, B., Enzymatic function of nitric oxide synthases. Cardiovasc Res, 43(3):521-31, 1999.

27.Guzik, T.J., Korbut, R. and Adamek-Guzik, T., Nitric oxide and superoxide in inflammation and immune regulation. $J$ Physiol Pharmacol, 54(4):469-87, 2003.

28.Hoşnuter, M., Gürel, A., Babucçu, O., Armutcu, F., Kargi, E. and Işikdemir, A., The effect of CAPE on lipid peroxidation and nitric oxide levels in the plasma of rats following thermal injury. Burns, 30(2):1215, 2004.

29.Sehirli, O., Sener, E., Sener, G., Cetinel, S., Erzik, C. and Yeğen, B.C., Ghrelin improves burn-induced multiple organ injury by depressing neutrophil infiltration and the release of pro-inflammatory cytokines. Peptides, 29(7):1231-40, 2008.

30.Amang, P.A., Tan, P.V., Patamaken, S.A. and Mefe, M.N., Cytoprotective and antioxidant effects of the methanol extract of Eremomastax speciosa in rats. Afr $J$ Tradit Complement Altern Med, 11(1):16571, 2013.

31.Reiter, R.J., Tan, D.X., Terron, M.P., Flores, L.J. and Czarnocki, Z., Melatonin and its metabolites: new findings regarding their production and their radical 
scavenging actions. Acta Biochim Pol, 54(1):1-9, 2007.

32.Rodriguez, C., Mayo, J.C., Sainz, R.M., Antolín, I., Herrera, F., Martín, V. and Reiter, R.J., Regulation of antioxidant enzymes: a significant role for melatonin. $J$ Pineal Res, 36(1):1-9, 2004.

33.Polat, A. and Emre, M.H., Effects of melatonin or acetylsalicylic acid on gastric oxidative stress after bile duct ligation in rats. J Gastroenterol, 41(5):433-9, 2006.

34.Kwon, K.J., Kim, J.N., Kim, M.K., Lee, J., Ignarro, L.J., Kim, H.J., Shin, C.Y. and Han, S.H., Melatonin synergistically increases resveratrol-induced heme oxygenase-1 expression through the inhibition of ubiquitin-dependent proteasome pathway: a possible role in neuroprotection. J Pineal Res, 50(2):11023, 2011.

35.Niki, E., Do antioxidants impair signaling by reactive oxygen species and lipid oxidation products? FEBS Lett, 586(21):3767-70, 2012.

36.Ma, Q., Advances in mechanisms of antioxidation. Discov Med, 17(93):121-30, 2014.

37.Cevik, O., Oba, R., Macit, C., Cetinel, S., Kaya, O.T., Sener, E. and Sener, G., Lycopene inhibits caspase-3 activity and reduces oxidative organ damage in a rat model of thermal injury. Burns, 38(6):861$71,2012$.
HRISTOVA M., et al.

38.Sener, G., Sehirli, O., Velioğlu-Oğünç, A., Ercan, F., Erkanli, G., Gedik, N. and Yeğen, B.C., Propylthiouracil (PTU)induced hypothyroidism alleviates burninduced multiple organ injury. Burns, 32(6):728-36, 2006.

39.Gurel, A., Armutcu, F., Hosnuter, M., Unalacak, M., Kargi, E. and Altinyazar, C., Caffeic acid phenethyl ester improves oxidative organ damage in rat model of thermal trauma. Physiol Res, 53(6):675-82, 2004.

40.Bekyarova, G., Bratchkova, Y. and Hristova, M., Effect of melatonin on buminduced morphological changes in gastric mucosa. Journal of Biomedical and Clinical Research, 3(2):93-99, 2010.

41.Fredenburgh, L.E., Perrella, M.A. and Mitsialis, S.A., The role of heme oxygenase-1 in pulmonary disease. Am J Respir Cell Mol Biol, 36(2):158-65, 2007.

42.Bekyarova, G., Tzaneva, M. and Hristova, M., Heme Oxygenase-1 Expresion in Gastric Mucosa and Liver after Burns: Preliminary Immunohistochemical Study. $J$ Interdiscipl Histopathol, 1(5): 246-251, 2013.

43.Dulak, J. and Jozkowicz, A., Novel faces of heme oxygenase-1: mechanisms and therapeutic potentials. Antioxid Redox Signal, 20(11):1673-6, 2014. 